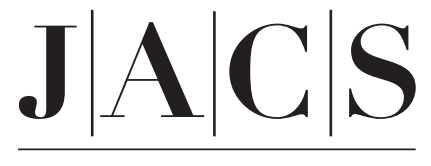

A R T I C L E S

Published on Web 03/04/2006

\title{
Cobalt Particle Size Effects in the Fischer-Tropsch Reaction Studied with Carbon Nanofiber Supported Catalysts
}

\author{
G. Leendert Bezemer, ${ }^{\dagger}$ Johannes H. Bitter, ${ }^{\dagger}$ Herman P. C. E. Kuipers, ${ }^{\ddagger}$

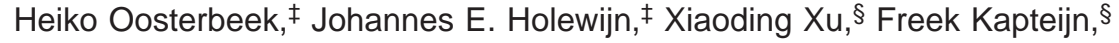 \\ A. Jos van Dillen, ${ }^{\dagger}$ and Krijn P. de Jong*, ${ }^{*}$ \\ Contribution from Inorganic Chemistry and Catalysis, Debye Institute, Utrecht University, \\ Sorbonnelaan 16, 3508 TB Utrecht, The Netherlands, Shell Global Solutions, P.O. Box 38000, \\ 1030 BN Amsterdam, The Netherlands, and Reactor and Catalysis Engineering, Faculty of \\ Applied Sciences, Delft University of Technology, Julianalaan 136, \\ 2628 BL Delft, The Netherlands
}

Received December 6, 2005; E-mail: k.p.dejong@chem.uu.nl

\begin{abstract}
The influence of cobalt particle size in the range of $2.6-27 \mathrm{~nm}$ on the performance in FischerTropsch synthesis has been investigated for the first time using well-defined catalysts based on an inert carbon nanofibers support material. X-ray absorption spectroscopy revealed that cobalt was metallic, even for small particle sizes, after the in situ reduction treatment, which is a prerequisite for catalytic operation and is difficult to achieve using traditional oxidic supports. The turnover frequency (TOF) for CO hydrogenation was independent of cobalt particle size for catalysts with sizes larger than $6 \mathrm{~nm}$ (1 bar) or $8 \mathrm{~nm}$ (35 bar), while both the selectivity and the activity changed for catalysts with smaller particles. At 35 bar, the TOF decreased from $23 \times 10^{-3}$ to $1.4 \times 10^{-3} \mathrm{~s}^{-1}$, while the $\mathrm{C}_{5+}$ selectivity decreased from 85 to $51 \mathrm{wt} \%$ when the cobalt particle size was reduced from 16 to $2.6 \mathrm{~nm}$. This demonstrates that the minimal required cobalt particle size for Fischer-Tropsch catalysis is larger $(6-8 \mathrm{~nm})$ than can be explained by classical structure sensitivity. Other explanations raised in the literature, such as formation of $\mathrm{CoO}$ or $\mathrm{Co}$ carbide species on small particles during catalytic testing, were not substantiated by experimental evidence from X-ray absorption spectroscopy. Interestingly, we found with EXAFS a decrease of the cobalt coordination number under reaction conditions, which points to reconstruction of the cobalt particles. It is argued that the cobalt particle size effects can be attributed to nonclassical structure sensitivity in combination with CO-induced surface reconstruction. The profound influences of particle size may be important for the design of new Fischer-Tropsch catalysts.
\end{abstract}

\section{Introduction}

In the Fischer-Tropsch (FT) reaction, $\mathrm{CO}$ and $\mathrm{H}_{2}$ are catalytically converted into hydrocarbons via surface polymerization. Using this process, clean transportation fuels can be produced from non-crude-oil feedstocks, and therefore, the FT process receives much attention both in academia and industry. ${ }^{1-6}$ Supported cobalt is well-known for its catalytic activity and selectivity in the FT reaction; however, improvements in activity can be envisaged as commercial FT catalysts have cobalt particle sizes around $20 \mathrm{~nm}^{7}$ In the quest for the development of more active catalysts, a rational strategy is to enhance the cobalt

\footnotetext{
Utrecht University.

$\doteqdot$ Shell Global Solutions.

$\S$ Delft University of Technology.

(1) Colley, S. E.; Copperthwaite, R. G.; Hutchings, G. J.; Terblanche, S. P.; Thackeray, M. M. Nature 1989, 339, 129-130.

(2) Schulz, H. Appl. Catal. A 1999, 186, 3-12.

(3) Jenkins, S. J.; King, D. A. J. Am. Chem. Soc. 2000, 122, 10610-10614.

(4) Dry, M. E. Catal. Today 2002, 71, 227-241.

(5) Turner, M. L.; Marsih, N.; Mann, B. E.; Quyoum, R.; Long, H. C.; Maitlis, P. M. J. Am. Chem. Soc. 2002, 124, 10456-10472.

(6) Liu, Z. P.; Hu, P. J. Am. Chem. Soc. 2002, 124, 11568-11569.

(7) Oukaci, R.; Singleton, A. H.; Goodwin, J. G. Appl. Catal. A 1999, 186, $129-144$
}

dispersion by decreasing the average particle size. Bartholomew ${ }^{8}$ and Yermakov ${ }^{9,10}$ pioneered this field in 1985, and later Iglesia and co-workers reported a large increase of activity when the cobalt particle size was decreased from 200 to 9 nm. ${ }^{11-13}$ They showed that the surface-specific activity, often referred to as turnover frequency (TOF), was not influenced by the cobalt particle size as such. However, going to even smaller cobalt particle sizes, the results reported in the literature are more scattered. Several research groups have reported that the TOF suddenly decreased for catalysts with cobalt particle sizes smaller than $10 \mathrm{~nm} .^{8-10,14-22}$ Other research groups did not

(8) Reuel, R. C.; Bartholomew, C. H. J. Catal. 1984, 85, 78-88.

(9) Lisitsyn, A. S.; Golovin, A. V.; Kuznetsov, V. L.; Yermakov, Y. I. Cl Mol. Chem. 1984, 1, 115-135.

(10) Lisitsyn, A. S.; Golovin, A. V.; Kuznetsov, V. L.; Yermakov, Y. I. J. Catal. 1985, 95, 527-538

(11) Iglesia, E.; Soled, S. L.; Fiato, R. A. J. Catal. 1992, 137, 212-224.

(12) Iglesia, E.; Soled, S. L.; Fiato, R. A.; Via, G. H. Stud. Surf. Sci. Catal. 1994, 81, 433.

(13) Iglesia, E. Appl. Catal. A 1997, 161, 59-78.

(14) Bezemer, G. I.; van Laak, A.; van Dillen, A. J.; de Jong, K. P. Stud. Surf. Sci. Catal. 2004, 147, 259-264.

(15) Martinez, A.; Lopez, C.; Marquez, F.; Diaz, I. J. Catal. 2003, 220, 486499.

(16) Barbier, A.; Tuel, A.; Arcon, I.; Kodre, A.; Martin, G. A. J. Catal. 2001, 200, 106-116.

10.1021/ja058282w CCC: $\$ 33.50$ @ 2006 American Chemical Society 
observe this so-called cobalt particle size effect, while measuring catalysts with similar sizes. ${ }^{11-13,23-27}$ This controversy points to the need of a systematic study on the influence of size on FT performance, in particular, in the range below $10 \mathrm{~nm}$ using well-defined catalysts.

The chemical background of the possible cobalt particle size effects has remained largely unclear. Most authors assume the lower reducibility of small cobalt oxide clusters to be responsible for the lower activity, but also carbide formation and structure sensitivity have been suggested as causes for the cobalt particle size effects. ${ }^{8,25,28-30}$ It is likely that indeed in most of the studies the lower activities of catalysts with small particles were caused by lower reducibility as oxidic support materials were mainly used. With oxidic supports, irreducible mixed oxides, such as cobalt aluminate or cobalt silicate, can be formed during preparation and testing, especially when using highly dispersed catalysts. ${ }^{30-32}$ However, this implies that the support material may have masked the cobalt particle size effects. This suggests that research focused on intrinsic cobalt particle size effects is advantageously performed using an inert support material, such as graphitic carbon.

To study the intrinsic cobalt particle size effects on an inert support material, we made use of graphitic carbon nanofibers $(\mathrm{CNF})$, a pure and structured material with a large pore volume and surface area. ${ }^{33,34}$ Recently, we showed the promising performance of $\mathrm{Co} / \mathrm{CNF}$ catalysts for the FT reaction. ${ }^{14,35}$ Here we present a comprehensive study of the preparation and FT performance of a series of catalysts with cobalt particle sizes varying from 2.6 to $27 \mathrm{~nm}$. Characterization was done with TEM, TPR, $\mathrm{H}_{2}$ chemisorption, XPS, X-ray absorption spectroscopy (XAS), and XRF. Catalytic performances for FT were measured at 1 and 35 bar in fixed bed reactors, while in situ XAS was done at the former pressure.

\section{Experimental Section}

Support Material. Carbon nanofibers of the fishbone-type with a diameter of about $30 \mathrm{~nm}$ were grown from synthesis gas $\left(\mathrm{CO}\right.$ and $\left.\mathrm{H}_{2}\right)$ using a $5 \mathrm{wt} \% \mathrm{Ni} / \mathrm{SiO}_{2}$ growth catalyst. The preparation of the growth catalyst and the experimental growth conditions were previously

(17) Fu, L.; Bartholomew, C. H. J. Catal. 1985, 92, 376-387.

(18) Lee, J. H.; Lee, D. K.; Ihm, S. K. J. Catal. 1988, 113, 544-548.

(19) Ho, S. W.; Houalla, M.; Hercules, D. M. J. Phys. Chem. 1990, 94, 63966399.

(20) Saib, A. M.; Claeys, M.; van Steen, E. Catal. Today 2002, 71, 395-402.

(21) Soled, S. L.; Iglesia, E.; Fiato, R. A.; Baumgartner, J. E.; Vroman, H.; Miseo, S. Top. Catal. 2003, 26, 101-109.

(22) Jacobs, G.; Das, T. K.; Zhang, Y. Q.; Li, J. L.; Racoillet, G.; Davis, B. H. Appl. Catal. A 2002, 233, 263-281.

(23) Fernandez-Morales, I.; Guerrero-Ruiz, A.; Lopez-Garzon, F. J.; RodriguezRamos, I.; Moreno-Castilla, C. Appl. Catal. 1985, 14, 159-172.

(24) Lok, C. M. Stud. Surf. Sci. Catal. 2004, 147, 283-288.

(25) Johnson, B. G.; Bartholomew, C. H.; Goodman, D. W. J. Catal. 1991, $128,231-247$.

(26) Moreno-Castilla, C.; Carrasco-Marin, F. J. Chem. Soc., Faraday Trans. 1995, 91, 3519-3524.

(27) Khodakov, A. Y.; Griboval-Constant, A.; Bechara, R.; Zholobenko, V. L. J. Catal. 2002, 206, 230-241.

(28) Geerlings, J. J. C.; Zonnevylle, M. C.; De Groot, C. P. M. Surf. Sci. 1991 $241,315-324$.

(29) Schanke, D.; Hilmen, A. M.; Bergene, E.; Kinnari, K.; Rytter, E.; Adnanes, E.; Holmen, A. Energy Fuels 1996, 10, 867-872

(30) Li, J. L.; Jacobs, G.; Das, T.; Zhang, Y. Q.; Davis, B. Appl. Catal. A 2002, $236,67-76$

(31) van Berge, P. J.; van de Loosdrecht, J.; Barradas, S.; van der Kraan, A. M Catal. Today 2000, 58, 321-334.

(32) Jacobs, G.; Patterson, P. M.; Zhang, Y. Q.; Das, T.; Li, J. L.; Davis, B. H Appl. Catal. A 2002, 233, 215-226.

(33) de Jong, K. P.; Geus, J. W. Catal. Rev.-Sci. Eng. 2000, 42, 481-510.

(34) Serp, P.; Corrias, M.; Kalck, P. Appl. Catal. A 2003, 253, 337-358.

(35) Bezemer, G. L.; Falke, U.; van Dillen, A. J.; de Jong, K. P. Chem. Commun. 2005, 701-703 described by Toebes. ${ }^{36}$ Treatments of these "as synthesized" CNF for $2 \mathrm{~h}$ in $1 \mathrm{M} \mathrm{KOH}$ and in concentrated $\mathrm{HNO}_{3}$ resulted in purified and surface-oxidized $\mathrm{CNF}^{37}$

Catalyst Preparation. Different preparation methods, such as incipient wetness impregnation (IWI), ion adsorption (IA), and homogeneous deposition precipitation (HDP), were used in order to obtain a broad range of particle sizes with a relatively narrow particlesize distribution. Ion adsorption and incipient wetness impregnation were used for the synthesis of highly dispersed catalysts at low loading, while HDP and impregnation were used for the preparation of highly loaded catalysts with intermediate dispersion.

Two samples with 9 and $11 \mathrm{wt} \%$ cobalt were prepared by homogeneous deposition precipitation (HDP) ${ }^{38}$ In a double-wall vessel, $0.41 \mathrm{~g}$ of $\mathrm{Co}\left(\mathrm{CO}_{3}\right) \cdot 0.1 \mathrm{H}_{2} \mathrm{O}$ was dissolved in $12.5 \mathrm{~g}$ of $25 \mathrm{wt} \%$ ammonia to which $35.4 \mathrm{~g}$ of demineralized water and $2.55 \mathrm{~g}$ of $\left(\mathrm{NH}_{4}\right)_{2} \mathrm{CO}_{3}(\mathrm{pH}$ $\approx 10.9$ ) were added. After filtration, $2.0 \mathrm{~g}$ of support was suspended in the solution, and nitrogen flushing $\left(200 \mathrm{~mL} \cdot \mathrm{min}^{-1}\right)$ was started, meanwhile the temperature was raised from room temperature to 90 ${ }^{\circ} \mathrm{C}$. After $18 \mathrm{~h}$, the mixture was cooled to room temperature $(\mathrm{pH}=8)$ and subsequently filtered. The solid was washed three times with demineralized water and dried at $120^{\circ} \mathrm{C}$ in air and was coded HDP9. The other sample (HDP11) was prepared from $5 \mathrm{~g}$ of CNF suspended in $220 \mathrm{~mL}$ of demineralized water to which $4.35 \mathrm{~g}$ of $\mathrm{Co}\left(\mathrm{NO}_{3}\right)_{2} \cdot 6 \mathrm{H}_{2} \mathrm{O}$ was added. The temperature was increased to $90{ }^{\circ} \mathrm{C}$, after which 2.70 $\mathrm{g}$ of urea in $30 \mathrm{~mL}$ was added. After $18 \mathrm{~h}$, the reaction was complete, and the sample was collected as described above for HDP9.

Nine samples were prepared by incipient wetness impregnation (IWI) for which we first determined the total pore volume of the CNF by adding demineralized water to degassed CNF with a syringe until the support had a sticky appearance. Typically, $3 \mathrm{~g}$ of degassed CNF was impregnated with $2.34 \mathrm{~mL}$ of aqueous solution containing either cobalt nitrate or cobalt acetate. Five catalysts were prepared using ethanol as solvent and $\mathrm{Co}\left(\mathrm{NO}_{3}\right)_{2} \cdot 6 \mathrm{H}_{2} \mathrm{O}$ as precursor. Special care was taken in the latter case to prevent boiling of the added solution by working at 25 mbar and $5{ }^{\circ} \mathrm{C}$, while for aqueous impregnations 7 mbar and $25^{\circ} \mathrm{C}$ were used. Samples prepared by incipient wetness impregnation were coded with three letters indicating method, solvent, and precursor followed by the cobalt loading, for example, IEN5 referring to a $5 \mathrm{wt}$ $\%$ catalyst prepared by impregnation with cobalt nitrate dissolved in ethanol. A survey of all the catalysts with their designations and cobalt loadings is given in Table 1 in the Results and Discussion section.

One sample was prepared using an ion-adsorption method. The cobalt solution was prepared by dissolving $0.32 \mathrm{~g}$ of $\mathrm{CoCO}_{3}$ and $2.46 \mathrm{~g}$ of $\left(\mathrm{NH}_{4}\right)_{2} \mathrm{CO}_{3}$ in $250 \mathrm{~mL}$ of a diluted aqueous ammonia solution $(\mathrm{pH}=$ 11.2). In this dark-red solution, $3 \mathrm{~g}$ of CNF was suspended and stirred for $24 \mathrm{~h}$ at room temperature. After filtration, the sample encoded IOC1 was obtained.

All catalyst precursors were dried overnight in air at $120^{\circ} \mathrm{C}$. Catalysts were obtained after a $2 \mathrm{~h}$ reduction treatment at $350{ }^{\circ} \mathrm{C}$ using $10 \%$ $\mathrm{H}_{2} / \mathrm{N}_{2}$. This reduction temperature was selected from TPR experiments (data not shown), where reduction onsets of cobalt(II) oxide were apparent around $300{ }^{\circ} \mathrm{C}$. Reduction of the catalysts was followed by a passivation treatment at room temperature using a diluted $(0.1 \%)$ oxygen flow.

Catalyst Characterization. X-ray fluorescence experiments to determine the cobalt loading on the support were carried out on a Goffin Meyvis spectro X-lab 2000.

$\mathrm{N}_{2}$ physisorption measurements were performed using a Micromeritics Tristar Surface Area and Porosity analyzer with samples previously outgassed at $393 \mathrm{~K}$

(36) Toebes, M. L.; Bitter, J. H.; van Dillen, A. J.; de Jong, K. P. Catal. Today 2002, 76, 33-42.

(37) Toebes, M. L.; van Heeswijk, J. M. P.; Bitter, J. H.; van Dillen, A. J.; de Jong, K. P. Carbon 2004, 42, 307-315

(38) Bezemer, G. L.; Radstake, P. B.; Koot, V.; van Dillen, A. J.; Geus, J. W.; de Jong, K. P. J. Catal. 2006, 237, 291-302. 
Reduced and passivated samples were examined with transmission electron microscopy (TEM) in an FEI Tecnai12 operated at $120 \mathrm{kV}$ or in an FEI Tecnai20F operated at $200 \mathrm{kV}$. Samples were crushed and suspended in ethanol under ultrasonic vibration. A drop of this suspension was brought onto a holey carbon film on a copper grid. Metal particle sizes from TEM reported in Table 1 are surface-area averaged values ( $\sim 200$ particles) that have been corrected for the presence of a $\sim 3 \mathrm{~nm} \mathrm{CoO}$ layer on the passivated Co particles.

The XPS data for passivated samples were obtained with a Vacuum Generators XPS system using Al K $\alpha$ radiation. Shirley backgrounds were subtracted from the raw data to obtain the areas of the $\mathrm{C}_{1 \mathrm{~s}}$ and the $\mathrm{Co}_{2 \mathrm{p}}$ peaks. The $\mathrm{C}_{1 \mathrm{~s}}$ peak at $284.2 \mathrm{eV}$ was used to correct for charging effects $(\max 0.2 \mathrm{eV})$. The inelastic mean free path of photoelectrons generated inside cobalt oxide is only $1.4 \mathrm{~nm}$, so the intensity ratio $I_{\mathrm{Co}} / I_{\mathrm{C}}$ (in combination with the specific surface area of the support) can be used to calculate the metal oxide dispersion. Calculations to determine the cobalt dispersion of the catalysts were based on the papers by Kuipers et al. ${ }^{39,40}$ assuming hemispherical cobalt oxide particles. In a previous paper, we showed that cobalt present in the inner tubes of the CNF $(<15 \%)$ does not contribute to the Co signal, so we corrected for either the pore volume or the surface area of the inner tubes. ${ }^{41}$ Particle sizes from XPS reported in Table 1 have also been corrected for the contraction of $\mathrm{CoO}$ to $\mathrm{Co}$ that occurs upon reduction to enable comparison with values obtained with $\mathrm{H}_{2}$ chemisorption.

Hydrogen chemisorption measurements were carried out using a Micromeritics ASAP 2010C. Before each measurement, the sample was dried in vacuum at $120^{\circ} \mathrm{C}$ overnight. Samples were subsequently heated in flowing $\mathrm{H}_{2}$ with a heating rate of $5{ }^{\circ} \mathrm{C} / \mathrm{min}$ to the reduction temperature of $350^{\circ} \mathrm{C}$. A reduction time of $2 \mathrm{~h}$ was used, after which the samples were evacuated at that temperature for $30 \mathrm{~min}$. The $\mathrm{H}_{2}$ adsorption isotherms were measured at $150{ }^{\circ} \mathrm{C}$. The $\mathrm{H} / \mathrm{Co}$ ratios at zero pressure were found by extrapolation of the linear part of the isotherm. Particle size estimations are based on hemispherical geometry, assuming complete reduction and an $\mathrm{H} / \mathrm{Co}_{\mathrm{s}}$ adsorption stoichiometry of 1 , using the formula $d=81.6 \mathrm{~W} / \mathrm{X}$, with $d$ being the cobalt particle diameter (nm), $W$ the weight percentage of cobalt, and $X$ the total $\mathrm{H}_{2}$ uptake in micromoles per gram of catalyst. ${ }^{42}$

X-ray absorption spectroscopy (XAS) data were measured for the cobalt $K$-edge in transmission at beam line E4 of HASYLAB synchrotron in Hamburg. The beam line was equipped with a $\mathrm{Si}(111)$ double crystal monochromator which was detuned to $60 \%$ of the maximum intensity to avoid higher harmonics. A cobalt foil was simultaneously measured as a reference with a third ionization chamber. Samples were reduced in situ in $\mathrm{N}_{2} / \mathrm{H}_{2}(2 / 1 \mathrm{v} / \mathrm{v})$ in a dedicated cell and cooled to liquid nitrogen temperature to measure the EXAFS. Subsequently, the temperature was slowly raised to $220{ }^{\circ} \mathrm{C}$, and the gases were switched to $\mathrm{CO} / \mathrm{H}_{2}(1 / 2 \mathrm{v} / \mathrm{v})$ while measuring XANES. After $1 \mathrm{~h}$ of FT reaction, the gas was changed to $\mathrm{He}$ and cooled to liquid nitrogen to record the EXAFS spectra.

Spectra of cobalt foil, $\mathrm{CoO}$, and $\mathrm{Co}_{3} \mathrm{O}_{4}$ were measured as references. Extraction of the EXAFS data from the measured absorption spectra was performed with the XDAP code using standard procedures, averaging over three scans. ${ }^{43,44}$ Normalization was done at $50 \mathrm{eV}$ after the absorption edge using cubic spline routines for the background subtraction. Data for phase shifts and backscattering amplitudes for $\mathrm{Co}-\mathrm{Co}$ and $\mathrm{Co}-\mathrm{O}$ were obtained from FEFF8 calculations and calibrated by the experimental data of Co foil and $\mathrm{CoO}$. Data analysis

(39) Kuipers, H. P. C. E. Solid State Ion. 1985, 16, 15-21.

(40) Kuipers, H. P. C. E.; Van Leuven, H. C. E.; Visser, W. M. Surf. Interface Anal. 1986, 8, 235-242.

(41) Winter, F.; Bezemer, G. L.; van der Spek, C.; Meeldijk, J. D.; van Dillen, A. J.; Geus, J. W.; de Jong, K. P. Carbon 2005, 43, 327-332.

(42) Reuel, R. C.; Bartholomew, C. H. J. Catal. 1984, 85, 63-77.

(43) Vaarkamp, M.; Linders, J. C.; Koningsberger, D. C. Physica B 1995, 209, $159-160$.

(44) Koningsberger, D. C.; Mojet, B. L.; van Dorssen, G. E.; Ramaker, D. E. Top. Catal. 2000, 10, 143-155.

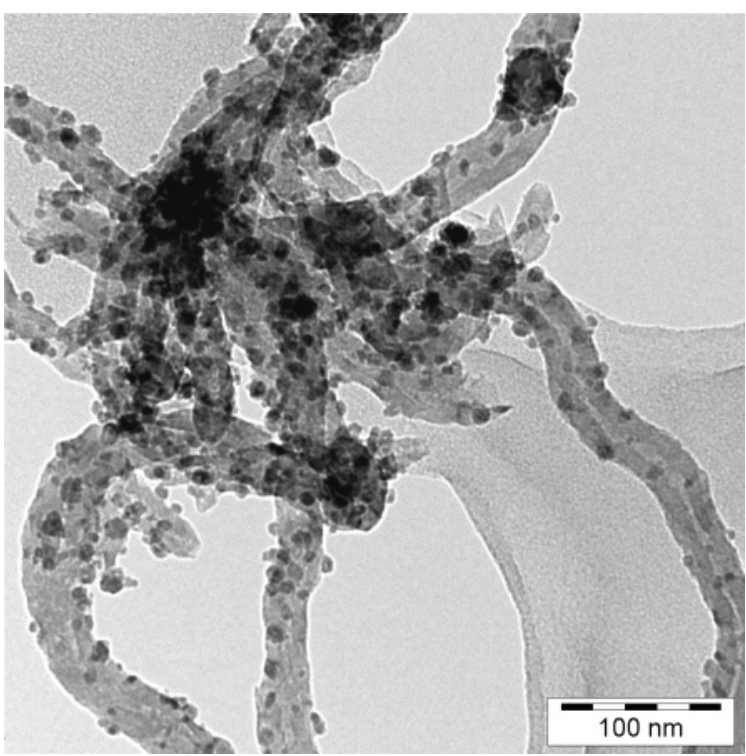

Figure 1. TEM image of HDP9 showing particles with sizes of around 14 $\mathrm{nm}$ distributed over the fibers.

of the $\mathrm{Co} / \mathrm{CNF}$ catalysts was performed by multiple shell fitting of the data applying $k^{1}$ and $k^{3}$ weighting using the difference file technique in $R$ space $(1.8-2.6 \AA)$ with the XDAP code. ${ }^{43,44}$

Catalytic Testing. Catalysts were tested at atmospheric pressure and at 35 bar. The measurements at 1 bar were carried out at $220^{\circ} \mathrm{C}$ using $\mathrm{CO} / \mathrm{H}_{2}(1 / 2 \mathrm{v} / \mathrm{v})$ after a reduction treatment at $350{ }^{\circ} \mathrm{C}$ for $2 \mathrm{~h}$ in $\mathrm{H}_{2}$ flow. Typically, $50 \mathrm{mg}$ of catalyst particles $(0.5-1.0 \mathrm{~mm})$ was diluted with $200 \mathrm{mg}$ of $\mathrm{SiC}$ particles $(0.2 \mathrm{~mm})$ to achieve isothermal plugflow conditions. Gas chromatography (GC) was used for online product analysis $\left(\mathrm{C}_{1}-\mathrm{C}_{20}\right)$ and to establish weight selectivities toward methane $\left(\mathrm{C}_{1}\right)$ and toward products with chain length of 5 and higher $\left(\mathrm{C}_{5+}\right)$. Catalysts were measured atmospherically at a CO conversion of $2 \%$, which was achieved by tailoring the space velocity. For the highpressure measurements, $0.25 \mathrm{~g}$ of catalyst $(150-212 \mu \mathrm{m})$ was diluted with $0.5-0.7 \mathrm{~g}$ of SiC. Catalytic data were obtained at 210 and 250 ${ }^{\circ} \mathrm{C}$ and a pressure of 35 bar using a flow of $\mathrm{CO} / \mathrm{H}_{2} / \mathrm{N}_{2}(33 / 66 / 6)$. The space velocity was adjusted to maximize $\mathrm{CO}$ conversions at $60-80 \%$. Both on-line and off-line product analyses were performed with GC. Reported catalytic data are obtained after at least 3 days of operation.

\section{Results and Discussion}

Characterization of the Support. The CNF were fishbonetype with the graphene sheets oriented in an angle to the main axis of the fiber. ${ }^{33}$ The fibers possessed an average external diameter of $30 \mathrm{~nm}$ and an inner core with a diameter of $7 \mathrm{~nm}$ (cf. Figure 1). From nitrogen physisorption, a total BET surface area of $161 \mathrm{~m}^{2} / \mathrm{g}$ was found. The samples did not contain micropores, and the total mesopore volume was $0.68 \mathrm{~g} / \mathrm{mL}$. A pore volume of $0.78 \mathrm{~g} / \mathrm{mL}$ was found when demineralized water was added to the support until they had a sticky appearance. The microscopic fibers were interwoven and had grown into macroscopic particles with an average size of $2 \mathrm{~mm}$. The density of a packed bed of this support material amounted to $0.47 \mathrm{~g} / \mathrm{mL}$.

Cobalt Particle Size. The cobalt metal loadings (XRF) varied from 0.77 to $22.0 \mathrm{wt} \%$ in the final catalysts. For the impregnated catalysts, the loading measured with XRF was very close to the value calculated from the cobalt intake. Four techniques were used to determine the cobalt particle sizes of the catalysts because all have their limitations. The cobalt particle sizes calculated from the hydrogen chemisorption varied from 4.3 to $25 \mathrm{~nm}$ (Table 1). In addition to chemisorption, we 
Table 1. Sample Codes, Preparation Methods, Cobalt Loadings, and Metallic Cobalt Particle Sizes as Determined by $\mathrm{H}_{2} \mathrm{Chemisorption}^{\circ}$ XPS, and TEM of the Various CNF-Supported Catalysts after Reduction at $350^{\circ} \mathrm{C}$

\begin{tabular}{|c|c|c|c|c|c|c|c|c|}
\hline sample & method, solvent & precursor & $\mathrm{Co}(\mathrm{wt} \%)$ & $\mathrm{H}_{2}$ ads. $^{a}$ & $\mathrm{Co} / \mathrm{C}(\mathrm{at} / \mathrm{at})^{b}$ & $\mathrm{H}_{2}(\mathrm{~nm})$ & XPS (nm) & TEM (nm) \\
\hline HDP11 & HDP & nitrate & 11 & 36 & 0.010 & 25 & 27 & $\sim 30$ \\
\hline HDP9 & HDP & carbonate & 9.0 & 53 & 0.021 & 12.5 & 12.8 & 14 \\
\hline IWN22 & IWI, water & nitrate & 22 & 111 & 0.047 & 16 & 16 & \\
\hline IWN13 & IWI, water & nitrate & 13 & 124 & 0.031 & 8.5 & 8.5 & 7.5 \\
\hline IWN10 & IWI, water & nitrate & 9.9 & 82 & 0.022 & 9.8 & 10 & \\
\hline IEN8 & IWI, ethanol & nitrate & 7.5 & 89 & 0.023 & 6.9 & 5.9 & \\
\hline IEN5 & IWI, ethanol & nitrate & 5.4 & 91 & 0.017 & 4.9 & 5.3 & \\
\hline IEN4 & IWI, ethanol & nitrate & 3.7 & 69 & 0.013 & 4.4 & 4.7 & 3.6 \\
\hline IEN1 & IWI, ethanol & nitrate & 1.1 & 20 & 0.0036 & 4.3 & 4.5 & \\
\hline IWA4 & IWI, water & acetate & 4.2 & 54 & 0.015 & 6.1 & 4.1 & 3.7 \\
\hline IWA1 & IWI, water & acetate & 1.0 & 2.5 & 0.0073 & 31 & 2.6 & 2.5 \\
\hline IOC1 & IA, water & carbonate & 0.8 & 13 & 0.0034 & 5.5 & 3.0 & \\
\hline
\end{tabular}

${ }^{a} \mathrm{H}_{2}$ ads. in $\mu \mathrm{mol}_{\mathrm{H}_{2}} \cdot \mathrm{g}_{\mathrm{cat}}{ }^{-1} \cdot{ }^{b} \mathrm{Co} / \mathrm{C}$ (at/at) obtained from XPS.

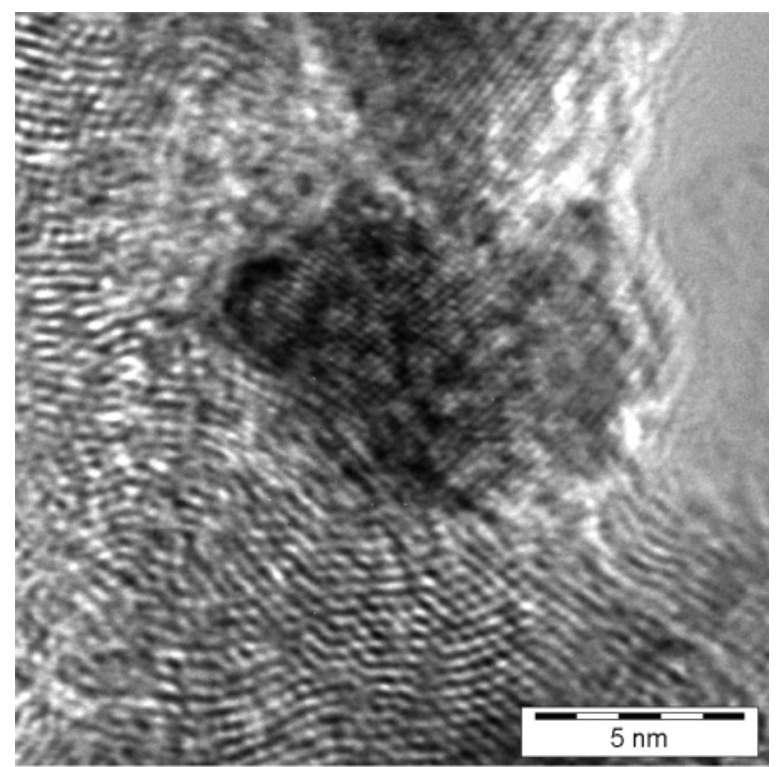

Figure 2. HR-TEM image of reduced and passivated IEN8 showing the graphite lattice $(0.34 \mathrm{~nm})$ and lattice planes of $\mathrm{CoO}(0.21 \mathrm{~nm})$.

used quantitative XPS to measure the cobalt dispersion. The $\mathrm{Co} / \mathrm{C}$ atomic ratios varied from 0.0034 to 0.047 , from which cobalt particle sizes varying from 2.6 to $27 \mathrm{~nm}$ were obtained (Table 1). Catalysts prepared by HDP possessed the largest cobalt particle sizes, followed by samples obtained with impregnation. Cobalt size for impregnated catalysts decreased with cobalt weight loading and was even lower when ethanol was used as solvent, as in this case better wetting with the $\mathrm{CNF}$ surface was achieved. Very small cobalt particles of around 3 nm were obtained with cobalt acetate as precursor, which is a chelating ligand that often favors dispersion ${ }^{45}$ and with ion adsorption.

With TEM, we found that the particle-size distributions in the catalysts were rather narrow with standard deviations of at most $20 \%$ of the average size. In Figures $1-4$, representative TEM images are shown for HDP9, IEN8, IEN4, and IWA1 after reduction and passivation. In Figure 1, rather long fibers are visible that have been decorated with cobalt particles. In the HR-TEM image of IEN8, depicted in Figure 2, apart from the graphite layers with a lattice distance of $0.34 \mathrm{~nm}$, the smaller lattice distance of $\mathrm{CoO}(0.21 \mathrm{~nm})$ is discernible, pointing toward

(45) van Dillen, A. J.; Terorde, R.; Lensveld, D. J.; Geus, J. W.; de Jong, K. P. J. Catal. 2003, 216, 257-264. reoxidation during the passivation treatment. In Figure 3, cobalt particles with uniform diameters are visible for IEN4 both at medium and at high resolution. Very small particles are found in IWA1 (Figure 4) with limited contrast in the TEM because the particles had been reoxidized completely.

Also from the EXAFS data of the in situ reduced IWA1 and IEN4 (Table 2), we could obtain cobalt particle sizes. The obtained Co-Co coordination numbers were 9.5 (IWA1) and 10.1 (IEN4) that correspond with particle sizes of 1.7 and 2.7 $\mathrm{nm}$, respectively. ${ }^{46}$ The error in the coordination number found with EXAFS is estimated to be around $10 \% .{ }^{47}$ For our catalysts, with rather high coordination numbers, this results in a particle size range from 1.2 to $3 \mathrm{~nm}$ for IWA 1 and from 1.4 to $5 \mathrm{~nm}$ for IEN4.

For catalysts with moderate to large XPS particle sizes (4.5$27 \mathrm{~nm}$ ), a close agreement with the results of hydrogen chemisorption was obtained, which was further supported by TEM (Table 1). For the catalysts with sizes smaller than 4.5 $\mathrm{nm}$, a discrepancy with the results obtained with hydrogen chemisorption was found (e.g., IWA1 $=2.6$ vs $31 \mathrm{~nm}$ ). Since the TEM results coincide with the XPS, the latter values can be used for all catalysts. Hydrogen chemisorption uptake depends on temperature, ${ }^{42}$ and the low uptake for samples with small cobalt particles might indicate that they require a different temperature. The particle sizes found with EXAFS for IWA1 and IEN4 display considerable uncertainty but are in agreement with sizes from XPS. In the remaining of this paper, particle sizes reported have been based on XPS unless stated otherwise.

Chemical State of Cobalt Prior to Catalytic Testing. The Fischer-Tropsch reaction proceeds only on metallic cobalt; however, incomplete reduction is often the case especially with small cobalt precursor particles. ${ }^{48}$ Therefore, we studied the oxidation state of cobalt of two highly dispersed catalysts with XAS. In Figure 5, the XANES spectra of IWA1 and IEN4 measured after in situ reduction are plotted together with the spectra of $\mathrm{CoO}$ and $\mathrm{Co}$ foil. The reference compounds are markedly different from each other with a far more intense white line for $\mathrm{CoO}$ as compared to Co. The XANES spectra of IEN4 and IWA1 (sizes $=4.7$ and $2.6 \mathrm{~nm}$ ) closely resembled the cobalt foil, with only a small difference in the $7725-7735 \mathrm{eV}$ region. The foil showed here two peaks that were well-resolved with a

(46) Arcon, I.; Tuel, A.; Kodre, A.; Martin, G.; Barbier, A. J. Synchrotron Radiat. 2001, 8, 575-577.

(47) de Graaf, J.; van Dillen, A. J.; de Jong, K. P.; Koningsberger, D. C. J. Catal. 2001, 203, 307-321.

(48) Sun, S.; Fujimoto, K.; Yoneyama, Y.; Tsubaki, N. Fuel 2002, 81, $1583-$ 1591. 
A

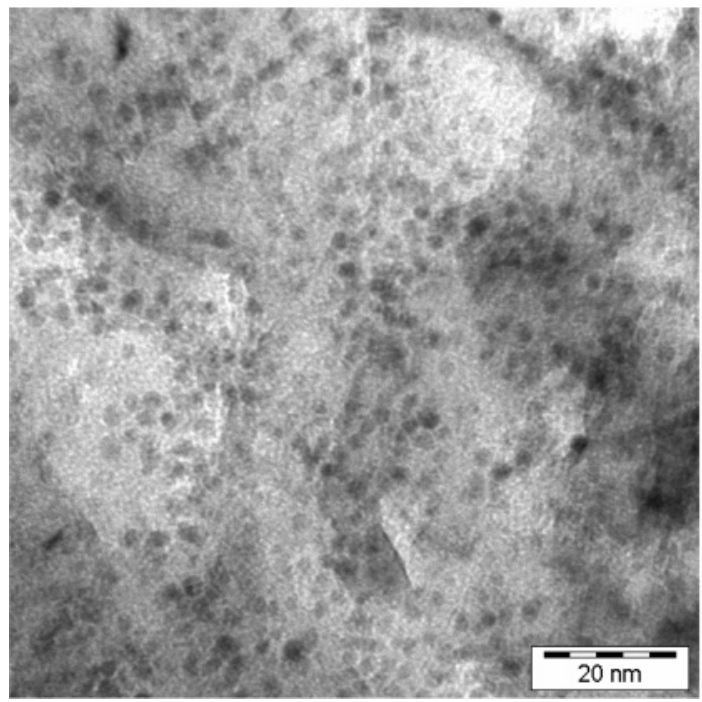

B

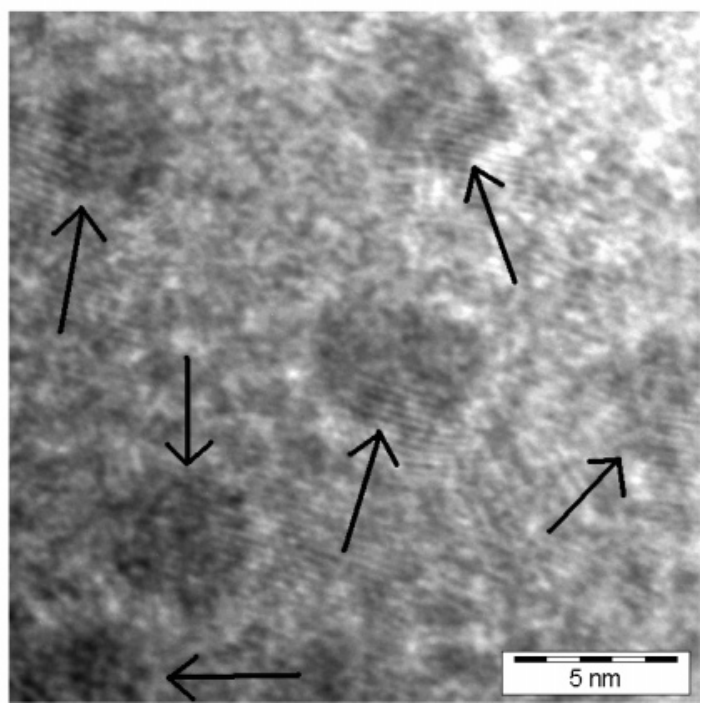

Figure 3. TEM images of reduced and passivated IEN4 showing spherical cobalt oxide particles distributed over the support at (A) medium resolution and (B) high resolution; particles of $\sim 4 \mathrm{~nm}$ indicated by arrows.

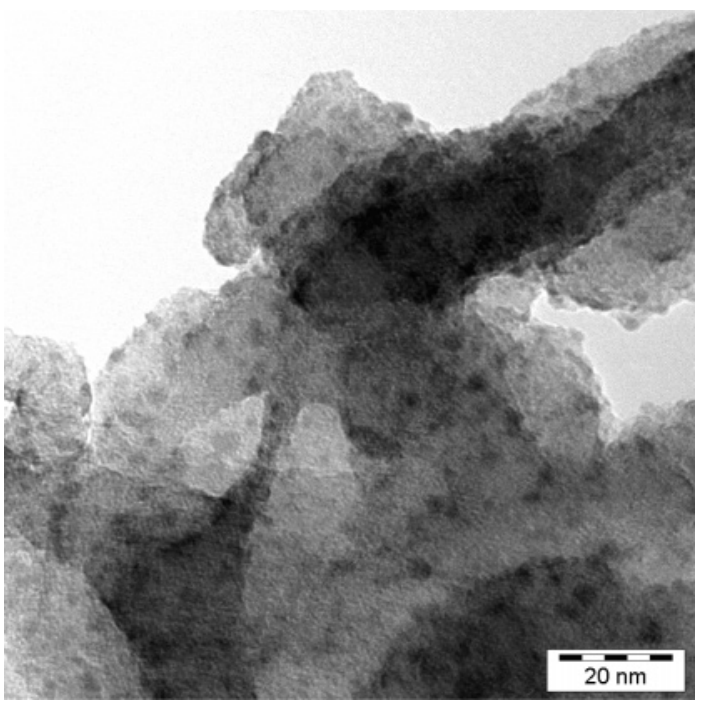

Figure 4. TEM image of IWA1 showing the presence of small cobalt oxide particles distributed over the support.

Table 2. Fit Parameters of the First Co-Co Shell of IEN4 and IWA1 after in situ Reduction (Red) and after $1 \mathrm{~h}$ in situ Catalysis (FT) $\left(\Delta k=3.3-12 \AA^{-1}, \Delta R=1.8-2.6 \AA\right)^{a}$

\begin{tabular}{lrrrrrrr}
\hline & & & & & \multicolumn{2}{c}{$k^{3}$ Variance } & \\
\cline { 7 - 8 } \multicolumn{1}{c}{ catalyst } & $N$ & $R(\AA)$ & $\Delta \sigma_{2}\left(\AA^{2}\right)$ & $\Delta E_{0}(\mathrm{eV})$ & $\mathrm{Im}$. & \multicolumn{1}{c}{ Abs. } & size $(\mathrm{nm})^{\mathrm{a}}$ \\
\hline IEN4 Red & 10.1 & 2.48 & $9.9 \times 10^{-4}$ & -0.78 & 0.0042 & 0.0150 & $2.7(1.4-5)$ \\
IEN4 FT & 9.5 & 2.48 & $1.3 \times 10^{-3}$ & 0.92 & 0.0048 & 0.0120 & \\
IWA1 Red & 9.5 & 2.48 & $7.7 \times 10^{-4}$ & -1.00 & 0.0025 & 0.0051 & $1.7(1.2-3)$ \\
IWA1 FT & 8.8 & 2.48 & $8.8 \times 10^{-4}$ & -1.01 & 0.0077 & 0.0125 & \\
\hline
\end{tabular}

${ }^{a}$ The cobalt particle size and size range have been derived from $N$ and $N \pm \Delta N$, respectively.

higher intensity for the second one, while for the catalysts, these peaks were flattened and had similar heights. This difference can be related to different crystal structures in catalysts and foil. The cobalt foil displays the characteristics of the hcp structure, while the pattern of the catalysts can be explained by the presence of a mixture of fcc (stable only for small particles) and hcp or bcc cobalt. ${ }^{42,49}$ If these catalysts contain some $\mathrm{CoO}$, it was estimated to be less than $3 \%$ using linear combinations

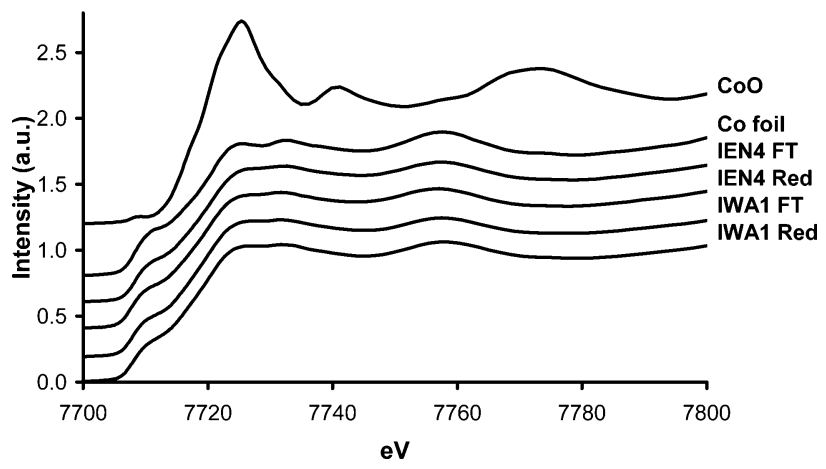

Figure 5. Normalized XANES spectra after in situ reduction ("Red") and after in situ FT ("FT") synthesis for IEN 4 and IWA1 plotted together with spectra of $\mathrm{CoO}$ and $\mathrm{Co}$ foil.

of $\mathrm{CoO}$ and $\mathrm{Co}$ foil. By the same token, we can exclude the presence of similar amounts of $\mathrm{CoC}_{2}$ in the catalysts. ${ }^{50}$

The EXAFS results in Table 2 show a $\mathrm{Co}-\mathrm{Co}$ bond distance of $2.48 \AA$, which is slightly lower than the bulk distance of $2.49 \AA$ we measured for the cobalt foil. From the Fourier transform magnitudes of cobalt foil and IEN4 (Figure 6), it can be seen that IEN4 has a lower intensity at the first Co-Co shell at $2.5 \AA$. For all analyses, the quality of the fit is quantified by the variances. The variance of the fit of the absolute part and the imaginary part is below 1 and $1.5 \%$, respectively. Using the difference file technique, no $\mathrm{Co}-\mathrm{O}$ or $\mathrm{Co}-\mathrm{C}$ contributions were found in the data, showing that, within the experimental error of $10 \%$, the samples were metallic.

Chemical State of Cobalt During and After Catalytic Testing. The cobalt oxidation state of the catalysts IEN4 and IWA1 was measured with XANES under reaction conditions at $\mathrm{H}_{2} / \mathrm{CO}=2 / 2 \mathrm{v} / \mathrm{v}, 1 \mathrm{bar}, 220^{\circ} \mathrm{C}$. With this technique, we did not detect any changes during the first hour of operation (data not shown). Spectra with better quality were obtained measuring at liquid nitrogen temperature. These spectra before and after catalytic testing are shown in Figure 5 and also do not exhibit

(49) Zhang, G. L.; Wu, Z. Y.; Li, A. G.; Wang, Y. S.; Zhang, J.; Abbas, M. I.; Hu, R.; Ni, X. B.; Tong, Y. P.; Hwu, Y. K. Phys. Rev. B 2004, 69.

(50) Touzain, P.; Nguessan, G. K.; Bonnin, D.; Kaiser, P.; Chouteau, G. Synth. Met. 1996, 79, 241-251. 


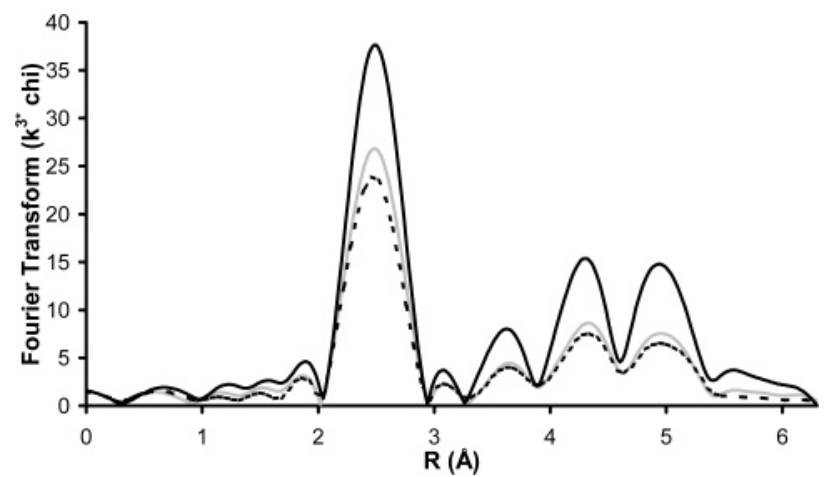

Figure 6. Fourier transform magnitude of the phase-corrected EXAFS data of the cobalt foil (black), IEN4 after reduction (gray), and IEN4 after $1 \mathrm{~h}$ of catalytic testing (dashed).

Table 3. Catalytic Properties Measured at $220^{\circ} \mathrm{C}, \mathrm{H}_{2} / \mathrm{CO}=2,1$ bara $^{a}$

\begin{tabular}{|c|c|c|c|c|c|c|}
\hline sample & $\begin{array}{l}\text { activity } \\
(\text { (CTY) }\end{array}$ & $\mathrm{HTOF}^{b}$ & $\mathrm{XTOF}^{c}$ & $\begin{array}{c}C_{1} \\
\text { (wt \%) }\end{array}$ & $\begin{array}{c}\mathrm{C}_{5+} \\
\text { (wt \%) }\end{array}$ & $\begin{array}{c}\mathrm{P} / \mathrm{O}_{8} \\
(\mathrm{~mol} / \mathrm{mol})\end{array}$ \\
\hline HDP11 & 0.64 & 9.6 & 10.6 & 42 & 23 & 13 \\
\hline HDP9 & 1.27 & 10.5 & 9.7 & 22 & 50 & 2.0 \\
\hline IWN22 & 1.21 & 12.0 & 11.5 & 41 & 24 & 13 \\
\hline IWN13 & 2.17 & 11.4 & 11.3 & 39 & 28 & 11 \\
\hline IWN10 & 1.74 & 10.5 & 10.7 & 40 & 28 & 11 \\
\hline IEN8 & 3.51 & 14.9 & 12.2 & 40 & 30 & 13 \\
\hline IEN5 & 2.51 & 7.5 & 8.0 & 41 & 30 & 21 \\
\hline IEN4 & 2.19 & 5.9 & 6.6 & 49 & 25 & 27 \\
\hline IEN1 & 0.96 & 2.5 & 2.7 & 51 & 20 & 51 \\
\hline IWA4 & 1.46 & 5.4 & 3.8 & 47 & 24 & 55 \\
\hline IWA1 & 0.80 & & 1.3 & 53 & 18 & 40 \\
\hline IOC1 & 0.79 & 2.3 & 1.5 & & & 52 \\
\hline
\end{tabular}

${ }^{a} \mathrm{CTY}=10^{-5} \mathrm{~mol}_{\mathrm{CO}} \cdot \mathrm{g}_{\mathrm{Co}}{ }^{-1} \cdot \mathrm{s}^{-1} \cdot{ }^{b} \mathrm{HTOF}=10^{-3} \mathrm{~s}^{-1}$ based on dispersion $\mathrm{H}_{2}$ chemisorption. ${ }^{c}$ XTOF $=10^{-3} \mathrm{~s}^{-1}$ based on dispersion from XPS.

a change. However, the Fourier transform of the $k^{3}$ weighted spectra (Figure 6) did change considerably as the intensity of the peaks decreased significantly, indicating the decrease of coordination number of the cobalt atoms. The EXAFS analysis revealed that the coordination number of the first $\mathrm{Co}-\mathrm{Co}$ shell decreased with $6-7 \%$ after the FT synthesis and the DebyeWaller factor increased, while other parameters were not influenced (Table 2). These changes indicate a reconstruction of the cobalt particles during FT synthesis (see General Discussion).

In IWA1 and IEN4, the fraction of cobalt present at the surface can be calculated to be 36 and $21 \%$, respectively, which implies that surface oxidation during FT synthesis would give rise to a substantial increase of the peak at $7725 \mathrm{eV}$ and the formation of $\mathrm{Co}-\mathrm{O}$ contributions in the EXAFS spectra. The absence of these changes indicates that neither bulk oxidation nor substantial surface oxidation had occurred during FT operation. The same reasoning holds for the absence of cobalt carbides ${ }^{50}$ from which it can be concluded that also carburization of the cobalt particles was not apparent.

Catalytic Performance at $\mathbf{1}$ bar. Activity and selectivity were measured at $2 \% \mathrm{CO}$ conversion (except IWA1 and IOC1), and values of the catalysts are listed in Table 3. In Figure 7, the cobalt-specific activity is plotted versus the cobalt particle size. Going from $27 \mathrm{~nm}$ (HDP11) to about $6 \mathrm{~nm}$ (IEN8), the activity increases from 0.64 to $3.51 \times 10^{-5} \mathrm{~mol}_{\mathrm{CO}} \cdot \mathrm{g}_{\mathrm{Co}}{ }^{-1} \cdot \mathrm{s}^{-1}$. This increase in activity correlates well with the higher specific cobalt surface areas. For catalysts with cobalt particle sizes smaller than $6 \mathrm{~nm}$, the activity decreases quite rapidly to 0.80

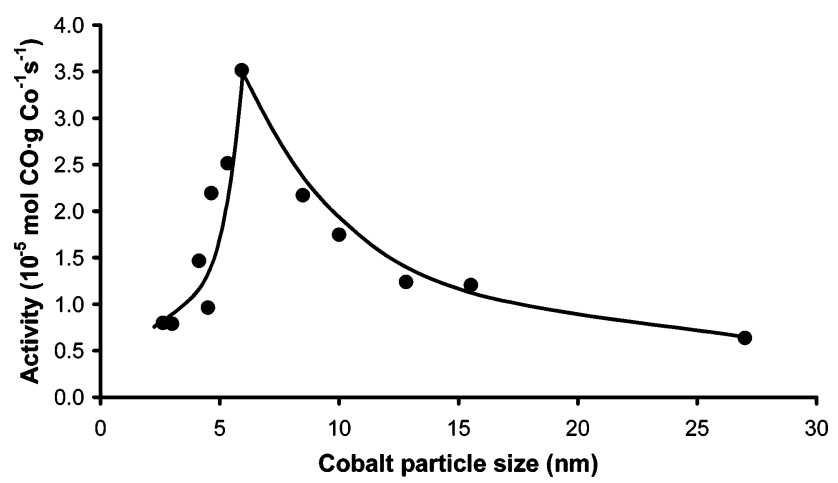

Figure 7. The influence of cobalt particle size on activity normalized to the cobalt loading $\left(220^{\circ} \mathrm{C}, \mathrm{H}_{2} / \mathrm{CO}=2,1\right.$ bar $)$.

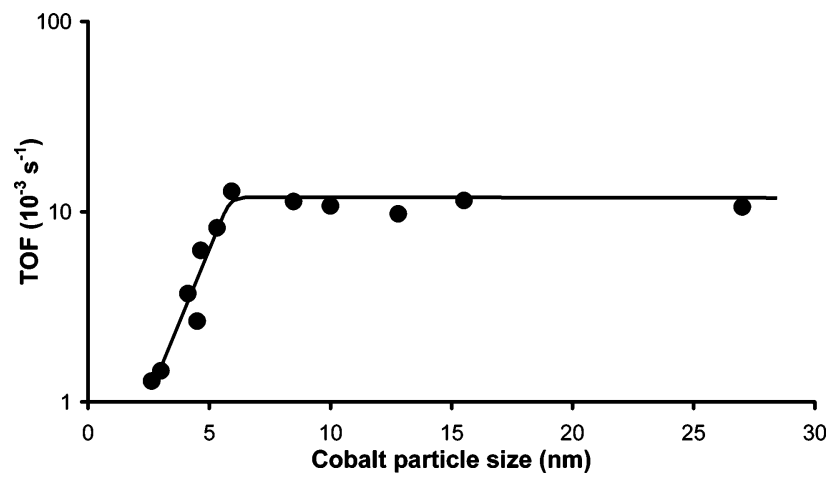

Figure 8. The influence of cobalt particle size on the TOF $\left(220{ }^{\circ} \mathrm{C}, \mathrm{H}_{2} /\right.$ $\mathrm{CO}=2,1$ bar).

$\times 10^{-5} \mathrm{~mol}_{\mathrm{CO}} \cdot \mathrm{g}_{\mathrm{Co}}{ }^{-1} \cdot \mathrm{s}^{-1}$ for IWA1. The surface-specific activities (TOF) were calculated using both the dispersion obtained from $\mathrm{H}_{2}$ chemisorption (HTOF) and that from XPS (XTOF) and are given in Table 3. The TOF data based on the XPS dispersion have been plotted in Figure 8 from which it becomes clear that the TOF is rather constant with a value of around $10^{-2} \mathrm{~s}^{-1}$ for cobalt particles ranging from 6 to $27 \mathrm{~nm}$. For smaller particle sizes, the TOF steeply decreases to a value close to $10^{-3} \mathrm{~s}^{-1}$ for IWA1.

At 1 bar total pressure, a methane selectivity of around 40 wt $\%$ and a $\mathrm{C}_{5}$ - selectivity of around $25 \mathrm{wt} \%$ were observed (Table 3), values that are typical for unpromoted cobalt catalysts at these conditions. The catalyst HDP9 exhibited a superior selectivity compared to that of all the other catalysts, with a methane selectivity of only $22 \mathrm{wt} \%$ and a $\mathrm{C}_{5+}$ selectivity of $50 \mathrm{wt} \%$, which are typical for promoted systems. ${ }^{35,51}$ Catalysts prepared with this method are currently under investigation to explain this behavior. In Figure 9, the methane selectivity is plotted as a function of cobalt particle size, excluding HDP9. It is clear that all catalysts with sizes smaller than $5 \mathrm{~nm}$ displayed progressively higher methane selectivity. For catalysts with high methane selectivities, also lower chain growth probabilities were found, resulting in an even lower selectivity to heavy weight hydrocarbons. The formation of methane indicates that dissociated hydrogen is sufficiently present on the catalyst surface. The higher selectivity to methane might also indicate a lower abundance of sites active for chain growth, resulting in more carbon species at the surface that become fully hydrogenated to methane.

(51) Morales, F.; de Groot, F. M. F.; Gijzeman, O. L. J.; Mens, A.; Stephan, O.; Weckhuysen, B. M. J. Catal. 2005, 230, 301-308. 


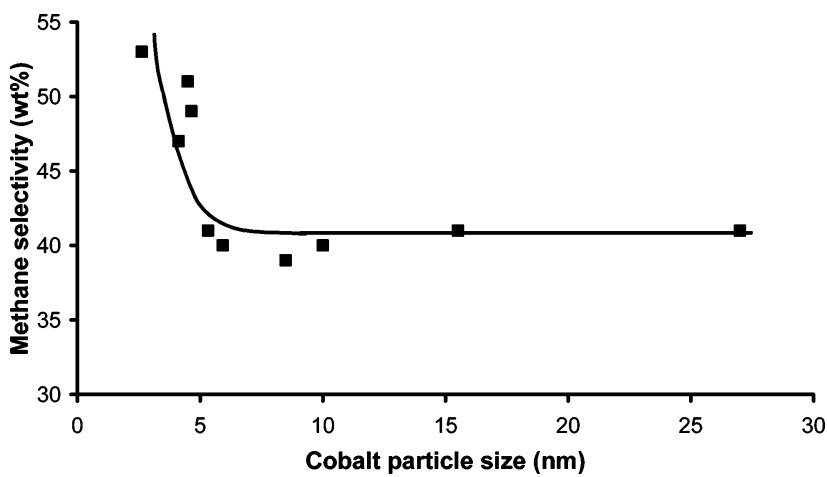

Figure 9. The influence of cobalt particle size on methane selectivity (220 ${ }^{\circ} \mathrm{C}, \mathrm{H}_{2} / \mathrm{CO}=2,1$ bar)

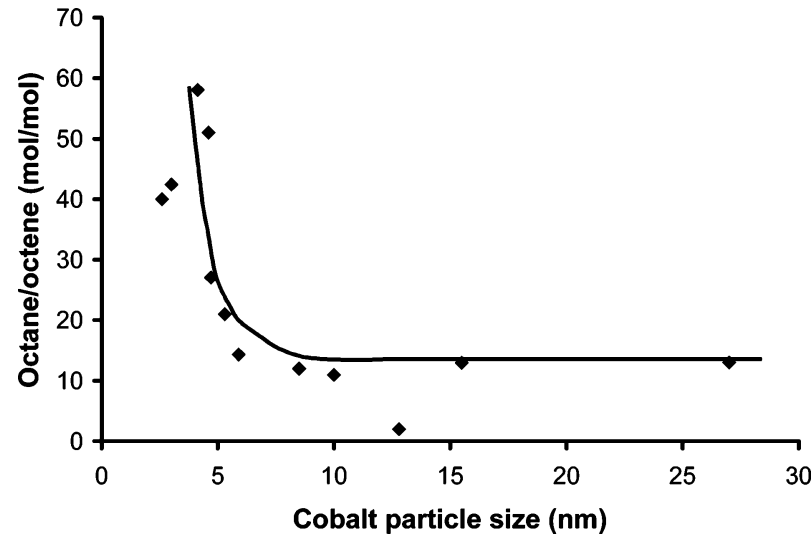

Figure 10. The influence of cobalt particle size on hydrogenation (220 ${ }^{\circ} \mathrm{C}, \mathrm{H}_{2} / \mathrm{CO}=2,1$ bar).

Another difference in the catalytic performance of the catalysts involves the selectivity to olefins and paraffins. In Table 3 and in Figure 10, the relation between cobalt particle size and the octane/octene ratio is given. The paraffin/olefin ratio at $\mathrm{C}_{8}$ was found to be representative for other carbon numbers too. Catalysts with a high $\mathrm{C}_{5}+$ selectivity, such as HDP9, had a much lower octane/octene ratio than the average value of 11 in this study. The general trend valid for all samples is that catalysts with cobalt particles smaller than $8 \mathrm{~nm}$ show a substantial increase of the paraffin over olefin ratio. The shift toward paraffins might indicate higher hydrogenation activities as it parallels the higher methane selectivity. However, part of the higher paraffin over olefin ratio could stem from different degrees of secondary hydrogenation caused by differences in space velocity in the catalytic tests. ${ }^{13}$ Other possible causes for differences in secondary hydrogenation, like diffusional limitations, ${ }^{52}$ could be excluded.

Spent catalysts contained $\mathrm{SiC}$ (used for catalysts bed dilution), making analysis with XPS, XRD, and $\mathrm{H}_{2}$ chemisorption cumbersome. Therefore, we used transmission electron microscopy to get an impression of cobalt dispersion after catalytic testing. In Figure 11, an image of HDP9 is shown obtained after 2 days of catalytic testing at 1 bar and $220{ }^{\circ} \mathrm{C}$. The cobalt particles were similarly sized as in the fresh sample (Figure 1), indicating the absence of sintering during catalytic operation. Also for other catalysts, we did not find larger cobalt particles in the spent catalyst, which indicates that the differences in catalytic performance were not induced by a particle-size-

(52) Kapteijn, F.; de Deugd, R. M.; Moulijn, J. A. Catal. Today 2005, 105, $350-356$.

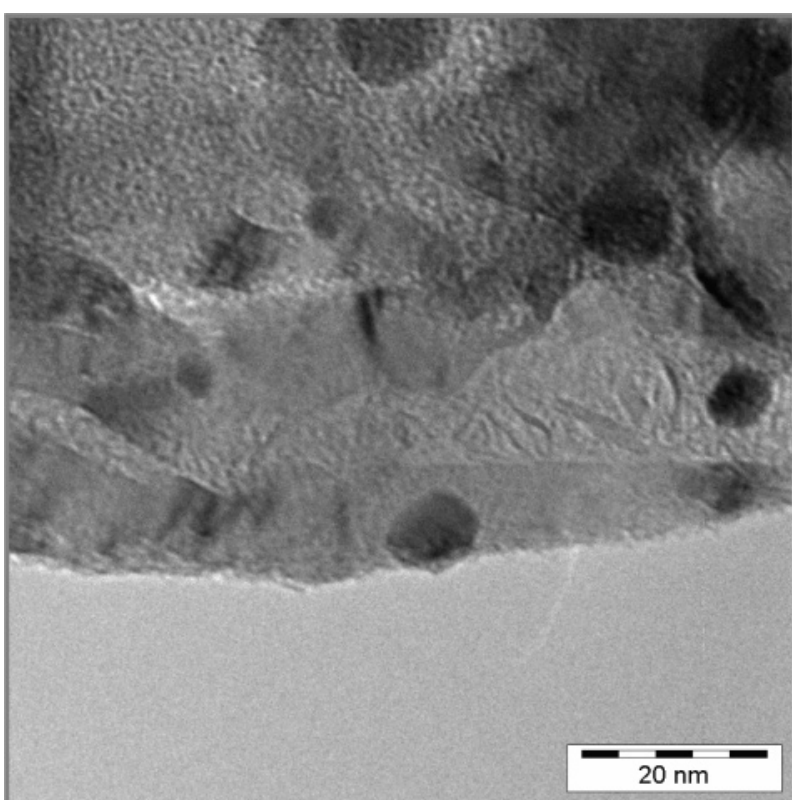

Figure 11. TEM image of spent HDP9 (1 bar, $\left.220^{\circ} \mathrm{C}, 48 \mathrm{~h}\right)$ indicating the absence of sintering.

Table 4. Catalytic Properties Measured at 210 and $250{ }^{\circ} \mathrm{C}, \mathrm{H}_{2} / \mathrm{CO}$ $=2,35$ bar

\begin{tabular}{lccccccr}
\hline sample & $\begin{array}{c}\text { temp } \\
\left({ }^{\circ} \mathrm{C}\right)\end{array}$ & $\begin{array}{c}\% \mathrm{CO} \\
\text { conv. }\end{array}$ & $\begin{array}{c}\text { activity } \\
(\mathrm{CTY})^{\mathrm{a}}\end{array}$ & $\mathrm{XTOF}^{b}$ & $\begin{array}{c}\mathrm{C}_{5+} \\
(\mathrm{wt} \%)\end{array}$ & $\begin{array}{c}\mathrm{CO}_{2}{ }^{\mathrm{c}} \\
(\%)\end{array}$ & WTY $^{d}$ \\
\hline IWN22 & 210 & 61 & 2.37 & 22.6 & 84.6 & 2.7 & 268 \\
IWN13 & 210 & 66 & 4.35 & 22.5 & 81.7 & 1.7 & 290 \\
IEN8 & 210 & 65 & 3.70 & 13.5 & 76.1 & 1.8 & 145 \\
IEN8 & 250 & 84 & 19.2 & 34.8 & 74.0 & 4.9 & 723 \\
IEN4 & 210 & 10 & 1.19 & 3.4 & & 20 & 21 \\
IEN4 & 250 & 67 & 7.69 & 22.0 & 60.9 & 8.5 & 151 \\
IWA1 & 210 & 4.3 & 0.88 & 1.4 & & $\sim 10$ & 5 \\
IWA1 & 250 & 13 & 5.83 & 9.4 & 50.7 & 5.1 & 26 \\
\hline
\end{tabular}

${ }^{a} \mathrm{CTY}=10^{-5} \mathrm{~mol}_{\mathrm{CO}} \cdot \mathrm{g}_{\mathrm{Co}}{ }^{-1} \cdot \mathrm{s}^{-1} \cdot{ }^{b} \mathrm{XTOF}=10^{-3} \mathrm{~s}^{-1}$ based on dispersion from XPS. ${ }^{c} \mathrm{CO}_{2}=\%$ of $\mathrm{CO}$ conversion. ${ }^{d} \mathrm{WTY}=\mathrm{g}_{\mathrm{CH}_{2}} \cdot \mathrm{kg}_{\mathrm{cat}}{ }^{-1} \cdot \mathrm{h}^{-1}$.

dependent sintering under reaction conditions. Moreover, TEM results of spent catalysts (cf. Figure 11) do not provide evidence of physical encapsulation of cobalt catalysts with either amorphous carbon or graphite.

Catalytic Performance at 35 bar. Five catalysts with particle sizes ranging from 2.6 to $13 \mathrm{~nm}$ were also studied at industrially relevant conditions (35 bar). We aimed for $\mathrm{CO}$ conversions of around 60\%; however, this was not possible for IWA1 and IEN4, catalysts with both small cobalt particle sizes and low metal loading. Slight deactivation was found with IWN22, while this was absent for the other catalysts. Table 4 lists the performances obtained at $210{ }^{\circ} \mathrm{C}$ for all five catalysts, and also at $250{ }^{\circ} \mathrm{C}$ for IWA1, IEN4, and IEN8. The activities at $210{ }^{\circ} \mathrm{C}$ varied from 0.88 to $4.35 \times 10^{-5} \mathrm{~mol}_{\mathrm{CO}} \cdot \mathrm{g}_{\mathrm{Co}}{ }^{-1} \cdot \mathrm{s}^{-1}$ and were dependent on cobalt particle size. In Figure 12, the TOF values at $210^{\circ} \mathrm{C}$ have been plotted versus the cobalt particle size. The TOF was constant for the samples with cobalt particle sizes larger than $\sim 8 \mathrm{~nm}$, whereas it started to decrease for catalysts with smaller sizes. We have added in Figure 12 data from Iglesia et al., ${ }^{13}$ which nicely coincide with our data for larger particles. Exploiting the benefits of an inert support material, we succeeded to study smaller particles that, however, revealed the far lower activities. Using these results, we comment on recent claims concerning the performance of $\mathrm{Co} / \mathrm{Al}_{2} \mathrm{O}_{3}$ catalysts with 3-5 nm cobalt crystallites. ${ }^{24}$ As the author did not report a 


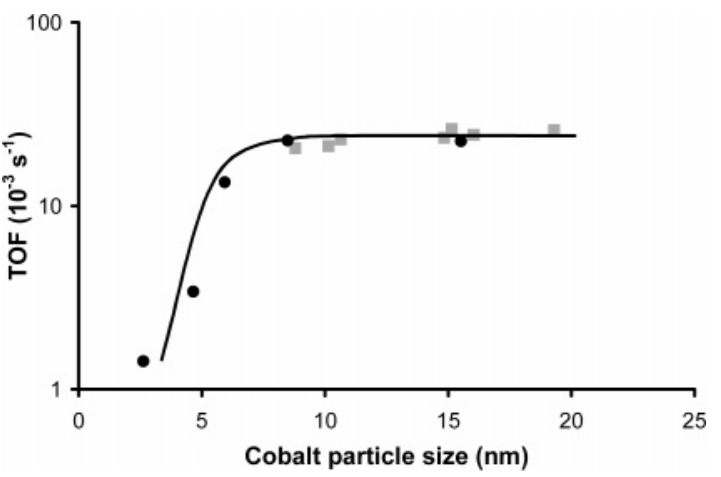

Figure 12. The influence of cobalt particle size on the TOF at 35 bar, 210 ${ }^{\circ} \mathrm{C}$ in black, data obtained from ref 13 are plotted in gray for comparison.

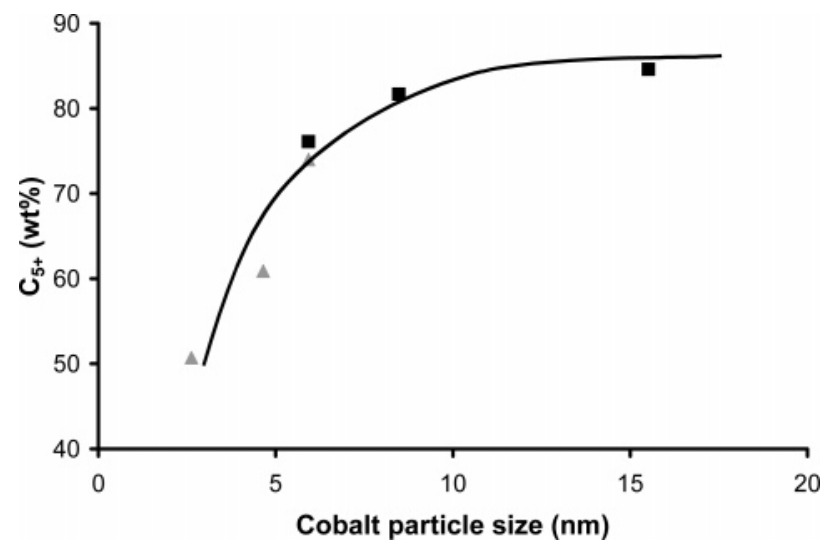

Figure 13. The influence of cobalt particle size on the $\mathrm{C}_{5+}$ selectivity measured at 35 bar; data markers in black at $210^{\circ} \mathrm{C}$ and in gray at $250{ }^{\circ} \mathrm{C}$.

particle size effect, we expect that his actual cobalt particle sizes were larger, say around $8 \mathrm{~nm}$. With this value, the reported activities and results from hydrogen chemisorption can be rationalized. ${ }^{24}$

It can be seen by comparison of Figures 8 and 12 that the catalytic data at 1 and 35 bar of pressure show the same general trend, with constant TOF for larger Co particles and size dependency for smaller crystallites. However, the catalyst with the optimum particle size at 1 bar (IEN8, $6 \mathrm{~nm}$ ) showed a lower TOF at 35 bar, which might indicate that the influence of particle size on performance is somewhat different at elevated pressures.

The selectivity for $\mathrm{CO}_{2}$ varied roughly from 2 to $20 \%$ of $\mathrm{CO}$ converted and was larger at low CO conversion, although no clear relation with particle size was apparent. Whether or not (surface) oxidation of cobalt plays a role for these relatively high $\mathrm{CO}_{2}$ selectivities is not clear. The $\mathrm{C}_{5}+$ selectivity (Figure 13) was clearly dependent on cobalt particle size and varied from 76 to 84 wt $\%$ at $210{ }^{\circ} \mathrm{C}$ and from 51 to 74 wt $\%$ at 250 ${ }^{\circ} \mathrm{C}$ with higher selectivities for larger particles. Furthermore, the product distribution of IWN22 $(16 \mathrm{~nm})$ was more shifted toward the heavy hydrocarbons than IWN13 $(\sim 8 \mathrm{~nm})$, that is, a larger chain growth probability, $\alpha$, as becomes clear from Figure 14. Note that the differences in selectivity are apparent for cobalt sizes larger than $\sim 8 \mathrm{~nm}$, where the activity was not influenced by size (compare Figures 12 and 13). One of the possible explanations of part of these differences is the 4-fold variation of the cobalt site density in the catalysts, which has been reported to affect the $\mathrm{C}_{5}+$ selectivity. ${ }^{53}$ On the basis of

(53) Iglesia, E.; Soled, S. L.; Baumgartner, J. E.; Reyes, S. C. Top. Catal. 1995, $2,17-27$.

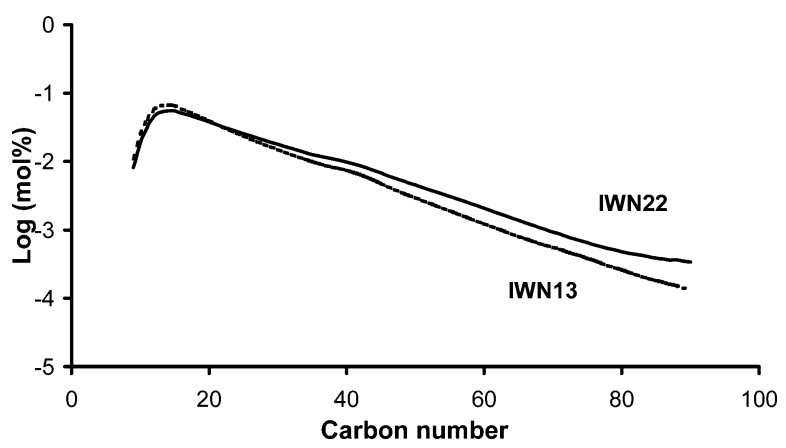

Figure 14. Product distribution of hydrocarbons collected in hot trap of IWN13 (dashed line) and IWN22 (solid line) after operation at 35 bar, $210{ }^{\circ} \mathrm{C}$

these literature data, the differences in cobalt site density can account for at most $10 \%$ change in $\mathrm{C}_{5}$ selectivity, which is about half of the current observation. The $\mathrm{CO}$ conversion level may have serious impact on selectivity too, but it was possible for all but one (IWA1) catalyst to reach similar CO conversions. Therefore, we ascribe the large differences in selectivity predominantly to the cobalt particle sizes of the catalysts.

General Discussion. In the literature, the change of the catalyst structure during FT reaction has been mentioned, resulting in the formation of either cobalt oxides or cobalt carbides. ${ }^{13,25,28-31,54-57}$ Small particles seem to be more susceptible to oxidation than larger particles, and oxidation during high-pressure catalytic testing has been reported to occur for catalysts with cobalt sizes smaller than $6 \mathrm{~nm} .{ }^{13}$ Recent thermodynamic calculations for a $\mathrm{p}_{\mathrm{H}_{2} \mathrm{O}} / \mathrm{p}_{\mathrm{H}_{2}}$ ratio of $1.5(75 \% \mathrm{CO}$ conversion) have shown that cobalt particles smaller than $4 \mathrm{~nm}$ can be oxidized during FT operation. ${ }^{55}$ Therefore, we cannot exclude that, with the measurements at high pressure, oxidation of cobalt has played a role for the two catalysts with smallest particle sizes. The catalytic tests at 1 bar and 2\% CO conversion resulted in $\mathrm{p}_{\mathrm{H}_{2} \mathrm{O}} / \mathrm{p}_{\mathrm{H}_{2}}$ ratios $(0.03)$ that did not enable the oxidation of cobalt. More importantly, during our in situ XAS experiments, no formation of $\mathrm{CoO}$ was observed for catalysts with small particle sizes.

Also, the formation of cobalt carbide species is a possible deactivation mechanism. For example, XPS studies after in situ catalytic testing have shown the presence of carbides on cobalt single crystals. ${ }^{25,28}$ However carbide formation with (small) cobalt crystals was not observed in our in situ XAS measurements.

To rationalize particle size effects, the influence of surface structure has been treated by Van Hardeveld and Hartog. ${ }^{58}$ Using models, the authors evaluated the fraction and type of surface atoms formed as a function of crystal size. They conclude that for metal particles with sizes below about $4 \mathrm{~nm}$ differences in specific activity can arise because different sites are exposed. The observed cobalt particle size effect in our work was present for catalysts with sizes up to $\sim 8 \mathrm{~nm}$ and hence cannot be explained by conventional structure sensitivity.

(54) Jacobs, G.; Das, T. K.; Patterson, P. M.; Li, J. L.; Sanchez, L.; Davis, B. H. Appl. Catal. A 2003, 247, 335-343.

(55) van Steen, E.; Claeys, M.; Dry, M. E.; van de Loosdrecht, J.; Viljoen, E. L.; Visagie, J. L. J. Phys. Chem. B 2005, 109, 3575-3577.

(56) Weller, S.; Hofer, L. J. E.; Anderson, R. B. J. Am. Chem. Soc. 1948, 70 799-801.

(57) Anderson, R. B.; Hall, W. K.; Krieg, A.; Seligman, B. J. Am. Chem. Soc. 1949, 71, 183-188.

(58) Van Hardeveld, R.; Hartog, F. Surf. Sci. 1969, 15, 189-230. 
We ascribe the influence of cobalt particle size on FT performance to nonclassical particle size effects in combination with the invasive character of $\mathrm{CO}^{59}$ during catalytic testing. Wilson and De Groot ${ }^{60}$ demonstrated by scanning tunneling microscopy the strong impact of synthesis gas on cobalt surfaces. Exposure of $\mathrm{Co}(0001)$ single crystals to synthesis gas at 4 bar caused severe surface reconstruction. Cobalt islands of about 2 $\mathrm{nm}$ lateral sizes and with a single-atom height were formed on the surface, which were subsequently converted into larger $(\sim 10$ $\mathrm{nm}$ ) triangular-shaped islands. In our EXAFS analysis, we measured a decreased Co coordination number due to synthesis gas feeding to $\mathrm{Co} / \mathrm{CNF}$, pointing to catalyst reconstruction, which is probably related to a change from hemispherical toward facetted particles. This is comparable to reconstruction of copper particles supported on $\mathrm{ZnO}$ upon reduction. ${ }^{61,62} \mathrm{We}$ propose that a minimum cobalt particle size is needed to stabilize the domains that contain the active sites for the FT synthesis. In theoretical calculations, it has been shown that monoatomic steps are essential to lower the activation barrier in FT synthesis. $6,63-65$ Apparently, for step sites on cobalt particles to act as stable FT sites, relatively large terraces are required. Taking into account that the FT reaction comprises of a large number of elementary steps, such as dissociation, hydrogenation, and insertion, it can be expected that a variety of sites may be needed. We speculate that on small crystallites the domains that combine these different active sites are not stable or they contain a nonoptimum ratio of the different sites. Concluding, we state that nonclassical structure sensitivity in combination with $\mathrm{CO}$ induced surface reconstruction may explain our data and is of importance in the design of new FT catalysts.

\section{Conclusions}

Using different synthesis methods and different weight loadings, a series of cobalt on carbon nanofiber catalysts with

(59) Schulz, H.; Nie, Z. Q.; Ousmanov, F. Catal. Today 2002, 71, 351-360.

(60) Wilson, J.; De Groot, C. J. Phys. Chem. 1995, 99, 7860-7866.

(61) Grunwaldt, J. D.; Molenbroek, A. M.; Topsoe, N. Y.; Topsoe, H.; Clausen, B. S. J. Catal. 2000, 194, 452-460.

(62) Hansen, P. L.; Wagner, J. B.; Helveg, S.; Rostrup-Nielsen, J. R.; Clausen, B. S.; Topsoe, H. Science 2002, 295, 2053-2055.

(63) Ciobica, I. M.; van Santen, R. A. J. Phys. Chem. B 2003, 107, 38083812 .

(64) Honkala, K.; Hellman, A.; Remediakis, I. N.; Logadottir, A.; Carlsson, A.; Dahl, S.; Christensen, C. H.; Norskov, J. K. Science 2005, 307, 555558

(65) Norskov, J. K.; Bligaard, T.; Logadottir, A.; Bahn, S.; Hansen, L. B.; Bollinger, M.; Bengaard, H.; Hammer, B.; Sljivancanin, Z.; Mavrikakis, M.; Xu, Y.; Dahl, S.; Jacobsen, C. J. H. J. Catal. 2002, 209, 275-278. cobalt particle sizes varying from 2.6 to $27 \mathrm{~nm}$ was prepared. The catalytic performance in the Fischer-Tropsch reaction was independent of cobalt particle size for catalysts with sizes larger than $6 \mathrm{~nm}$ ( 1 bar) or $8 \mathrm{~nm}$ (35 bar), but both activity and selectivity were strongly affected for catalysts with smaller cobalt particles. At 35 bar, the turnover frequency decreased from $23 \times 10^{-3}$ to $1.4 \times 10^{-3} \mathrm{~s}^{-1}$, while the $\mathrm{C}_{5+}$ selectivity decreased from 85 to 51 wt $\%$ when the particle size was decreased from 16 to $2.6 \mathrm{~nm}$. It is interesting to note that the catalytic data obtained at 1 bar were in good agreement with data at high pressure, which shows the relevance of the former measurements.

XAS data showed that both the reduced and the working catalysts were metallic and did not contain a measurable amount of cobalt carbides. The $\mathrm{Co}-\mathrm{Co}$ coordination number decreased after exposure to synthesis gas, which points toward catalyst reconstruction. Therefore, it was argued that the cobalt particle size effect has to be ascribed to a combination of $\mathrm{CO}$-induced surface reconstruction and nonclassical structure sensitivity. Cobalt-based FT catalysts apparently need a large particle size of about $6 \mathrm{~nm}$ in order to create optimal domains of active sites.

The presented data have a large consequence for the preparation of active cobalt-based Fischer-Tropsch catalysts. One should aim for catalysts with average cobalt particle sizes close to the optimum values of $6-8 \mathrm{~nm}$ as larger particles display a lower activity and smaller particles both a lower activity and a lower selectivity.

Acknowledgment. The authors kindly acknowledge A. van der Eerden (XRF, XAS), J.W. Geus (TEM), V. Koot (TPR and $\mathrm{H}_{2}$ chemisorption), A.J.M. Mens ( $\mathrm{N}_{2}$ physisorption and XPS), and P.B. Radstake (preparation of IWN10) and members from the XAFS team. We thank C.M.A.M. Mesters and M. Bezemervan de Pol for the fruitful discussions on this topic, and Shell Global Solutions for the financial support.

Note Added after ASAP Publication. Author affiliation footnotes were omitted in the version published ASAP March 4, 2006; the corrected version was published ASAP March 10, 2006.

JA058282W 